Psychology's Contributions to Understanding and Addressing Global Climate Change

\author{
Janet K. Swim \\ The Pennsylvania State University \\ Paul C. Stern \\ National Research Council \\ Thomas J. Doherty
}

Lewis \& Clark Graduate School of Education and Counseling

\author{
Susan Clayton \\ College of Wooster \\ Joseph P. Reser \\ Griffith University \\ Elke U. Weber \\ Columbia University \\ Robert Gifford \\ University of Victoria \\ and
}

George S. Howard

University of Notre Dame 
Psychology's Contributions to Understanding and Addressing Global Climate Change Global climate change poses one of the greatest challenges facing humanity in this century. This paper is a lead article to this special issue which follows from the American Psychological Association's task force report on The Interface between Psychology and Global Climate Change. In this article psychological dimensions of climate change are placed within the broader context of human dimensions of climate change by addressing human causes, consequences, and responses (adaptation and mitigation) to climate change and the links between these aspects of climate change and cognitive, affective, motivational, interpersonal, and organizational responses and processes. Characteristics of psychology that cross content domains and that make the field well suited for participation in understanding and addressing this challenge are highlighted. We also consider ethical imperatives for psychologists' involvement and provide suggestions for ways to increase psychologists' contribution to the science of climate change. 
Global climate change poses one of the greatest challenges facing humanity in this century. Earth's climate has changed in many ways over geological time, but for the first time, over the past century, human activity has become a significant cause of climate change. By burning fossil fuels, cutting and burning forests, and other environment impacting activities, human activity has changed the heat balance of Earth sufficiently that global average temperature has moved outside the range that has characterized the 10,000 years of recorded human history (Intergovernmental Panel on Climate Change, 2007a). This climate change "poses significant risks for — and in many cases is already affecting — a broad range of human and natural systems" (National Research Council, 2010a, p. 2). Because of physical time lags in the climate system, the impacts and human consequences will continue for many decades, and in some cases, many centuries (Solomon, Plattner, Knutti, \& Friedlingstein, 2009). Moreover, climate changes will take place in the context of the other sweeping social, technological and ecological transitions of the $21^{\text {st }}$ century (e.g., increases in population, urbanization, disparities in wealth; Stokols, Misra, Runnerstrom \& Hipp, 2009), making confident anticipation of the effects especially problematic. The current state of scientific knowledge on the causes and consequences of climate change is summarized in two recent major studies (Karl, Melillo, \& Peterson, 2009; National Research Council, 2010a).

Climate change is sometimes equated with global warming, but it involves much more than temperature change. The human activities that cause temperature change set in motion a series of associated phenomena: sea level rise, loss of polar sea ice, melting of continental glaciers, changes in precipitation patterns, progressive shifting in the habitats of species and the boundaries of ecosystems, acidification of the oceans, and more (Intergovernmental Panel on 
Climate Change, 2007a, 2007b; National Research Council, 2010b). These changes and impacts in turn create increasing risks to the planet's life support systems and to myriad species, including humankind.

The natural sciences have long been engaged with understanding environmental systems, including the physical and chemical processes that change Earth's heat balance, the ways these processes affect other parts of the global climate system, and the consequences of all these changes for physical and biological processes on land and in the waters. However, a second science of climate change has been developing for over a quarter of a century: the science of "human dimensions" of climate change (Chen, Boulding \& Schneider 1983; National Research Council, 1992; Stern, 1993). This field of science seeks to understand human activities that affect climate change, consequences of climate change that directly and indirectly affect people, human responses to anticipated and experienced climate change, and ways to help people respond effectively. Psychological dimensions are integral to human dimensions of climate change and have been a part of broader efforts by psychologists, perhaps most noticeably environmental psychologists, over the course of several decades to understand and address a range of environmental changes and problems (e.g., Gardner \& Stern, 2002; Koger \& Winter, 2010; Nickerson, 2003; Schmuck \& Schultz, 2002). A summary of relevant psychological research was provided by the American Psychological Association task force on The Interface between Psychology and Global Climate Change (Swim et al., 2009). The papers in this special issue follow from this task force report. The present paper provides an overview of these papers, a model that integrates this literature with the broader literature on human dimensions of climate change, and some general suggestions for psychologists who wish to contribute in this area. 
A simple conceptual model distinguishes climate systems (which are part of environmental systems) and human systems, and delineates the connections among them (see Figure 1, adapted from National Research Council, 1992; Stern, 1992). As noted on the left hand side of the model, people affect climate through activities (e.g., burning fossil fuels, clearing forests) that directly alter environmental conditions that change the climate. These activities, which have been called proximate human causes of climate change, are a result of a full range of cultural, economic, political, and social conditions and processes, depicted as "human systems" in the figure, and of psychological considerations noted in the middle of the model, which include human understanding of climate change, affective responses to climate change, and psychological motivations. Psychological considerations are often and appropriately treated as part of human systems. We separate them here to highlight them for a psychological audience. As depicted on the right side of the model, climate systems affect people through events that directly alter essential aspects of the environment that support humans and other living things by, for example, changing the frequency of storms and droughts, the availability of water, the viability of food crops, and the incidence of disease. Human consequences are also both psychological (e.g., distress) and social (e.g., intergroup relations) and are influenced by intraindividual cognitive, affective, and motivational processes as well as human systems at a larger scale. Responses to anticipated and experienced climate change are depicted as mitigation and adaptation, as noted in the bottom left and right corners of the model,. Efforts to mitigate or limit climate change are aimed at directly or indirectly altering the proximate causes of climate change. Adapting to climate change includes addressing the psychological and social impacts of both the threat and unfolding consequences of climate change. Cognitive, affective, and motivational processes affect mitigation and adaptation via the influence of psychological 
processes on human contributions, systems, and consequences. The direct and indirect impacts of these psychological processes on many elements of the figure illustrate that human dimensions of climate change are inherently psychological and social, and that psychology can offer knowledge and concepts that can help explain the human understanding, causes, consequences, and responses to climate change and help make the responses more effective.

\section{What Does Psychology Have to Offer?}

Over the past three decades, a number of research agendas have been developed for the human dimensions of global change, including climate change (e.g., Chen et al., 1983; Kates et al., 1985; National Research Council, 1992, 1999). Many efforts, including the American Psychological Association task force on climate change, have focused on the possible contributions of psychology (e.g., APA, 2009; Center for Research on Environmental Decisions, 2009; Fischhoff and Furby, 1983; Sjöberg, 1989; Clayton \& Brook, 2005; Clayton \& Myers, 2009; Cvetkovich \& Werner, 1994; Gifford, 2008; Kazdin, 2009; Spence, Pidgeon, \& Uzzell, 2009, Stern, 1992; Uzzell \& Räthzel, 2009; Vlek \& Steg, 2007). Environmental psychology provides the most obvious input. Gifford (2007) describes several themes in environmental psychology that have emerged over the last 50 years that are relevant to climate change: 1) an interest in informing and aiding public policy; 2) attention to technology both as a contributor to environmental problems and as a means to improve sustainability; 3) a tendency to value and benefit from multi-disciplinary collaborations and theories from other fields; and 4) expansion of interest to include multiple levels of analysis from small scale studies of individuals and small groups to larger-scale issues of sustainability. Yet, as past reviews indicate, many other subfields, such as cognitive, human factors, social, community, clinical, and counseling psychology, to name a few, have also provided valuable insights. Drawing on research from 
environmental psychology and other subfields, we elaborate on the model illustrated in Figure 1 by describing ways that psychological research has contributed to understanding and addressing: 1) human contributions to climate change, 2) psychological and interpersonal consequences of climate change, 3) mitigation and adaptation responses to climate change, and 4) human cognitive, affective, and motivational responses to climate change. Then we consider some overarching characteristics of psychological research and practice that are common to these four specific topical contributions.

First, psychology can help understand the human causes of climate change. Climate change is a quintessential commons problem: it involves collective action that is driven by individuals' short term benefits which degrades a long-term common good (National Research Council, 2002; for reviews of the psychological literature, see Gifford, 2008; Kopelman, Weber \& Messick, 2002). Human behavioral contributions to climate change occur through the use of goods and services that directly and indirectly result in fossil fuel consumption and the other biophysical changes that alter the climate. These activities, sometimes referred to as environmental consumption (Stern, 1997) are linked to consumer spending (economic consumption), although the two are not the same. As Swim, Clayton, and Howard (this issue) and Stern (this issue) show, psychologists can help conceptualize and better understand the predictors of environmental and economic consumption by providing psychological analyses of types of consumption behaviors and directing attention to behaviors that contribute the most to climate-driving emissions.

Implicit and explicit individual consumption decisions provide a critical link between contextual influences on decisions and the proximate behavioral causes of climate change (Swim et al., this issue). Individual level predictors of consumption decisions include personal 
capabilities (e.g., income, skills),motivations (e.g., connection to nature, perceptions of needs versus luxuries, basic psychological needs), and core values and beliefs. Attending to a variety of individual predictors can help explain instances in which individual and household behavior does not follow simple models of economic benefit maximization, such as when individuals and households fail to make energy-saving investments that would yield individual benefits at no cost or very attractive rates of financial return (Creyts, Granade, \& Ostrowski, 2010; Stern, 1986). Additionally, individual decisions are influenced by and operate through immediate and distal physical and social contexts in which they are embedded (Black, Stern, \& Elworth, 1985; Gifford, 2006; Bin \& Dowlatabadi, 2005). Contextual level predictors include aspects of physical infrastructure (e.g., the structure of human settlements, which influences the demand for motorized travel), available technology (e.g., machines that enable more rapid harvesting of resources such as trees and fish), geophysical events (e.g., drought, disasters, and storms), interpersonal contexts (e.g., social and cultural norms and comparisons) and cultural, economic, and political conditions (e.g., consumerism, cultural orientation toward time and nature, energy prices, government policies). Attending to the interface between individual decisions and contextual predictors can potentially help explain behavior when individual behaviors appear constrained by their cultural contexts, and also when households actively attempt to overcome these contexts, such as when they join counter-consumer movements (Bekin, Carrigan, \& Szmigin, 2005; Craig-Lees \& Hill, 2002).

Second, psychology can help understand the human consequences of climate change. These consequences obviously include biological impacts and hazards to physical health and to human settlements (Intergovernmental Panel on Climate Change, 2001b; World Health Organization, 2010). As Doherty and Clayton (this issue) note, they may also include direct and 
indirect psychological and interpersonal impacts. Although all of these potential impacts cannot be described with certainty and full clarity, the cumulative and interacting psychosocial effects of climate change may well be profound. Heat, extreme weather events, and increased competition for scarce environmental resources, compounded by preexisting inequalities and disproportionate impacts among groups and nations, affect interpersonal and intergroup behavior and can result in increasing stress and anxiety. Even in the absence of direct impacts, anticipation and concern about the threat of climate change may erode quality of life and threaten mental health. Individual and contextual features can influence the extent to which individuals and communities experience different impacts. Those who have the fewest social and economic resources are likely to be the most vulnerable to physical and psychological impacts. It may also be useful to also attend to possible positive consequences, such as people taking collective responsibility for solving a shared problem, that may aid individual coping and community responses.

Third, psychology can help understand and inform responses to climate change. The consequences of climate change both affect and are affected by the ways that individuals and communities adapt. Adaptation extends beyond making physical and structural adjustments to environmental changes. As Reser and Swim (this issue) note, adaptation also includes a range of coping actions that individuals and communities may take, as well as psychological processes (e.g., threat and response appraisals and emotion management and cognitive reframing responses) that both precede and follow behavioral responses. Adapting to, and coping with, climate change is dynamic; it involves many intrapsychic processes that influence reactions to (and preparations for) adverse impacts of climate change, including chronic environmental conditions and extreme events. Some relevant psychological processes include sense-making; causal and responsibility attributions for adverse climate change impacts; appraisals of impacts, 
resources, and possible coping responses; affective responses; and motivational processes related to needs for security, stability, coherence, and control. These processes are influenced by media representations of climate change, and by formal and informal social discourse that involves social construction, representation, amplification and attenuation of climate change risk and its impacts. These processes reflect and motivate both intrapsychic responses (e.g., emotion management, cognitive adaptation, problem solving) and individual and community responses. Individual and cultural variation influence all aspects of the process, providing context, world views, values, concerns, resilience, and vulnerability (Bloodhart \& Swim, 2010; Heath \& Gifford, 2006; Weber, 2010).

Psychologists are well-positioned to design, implement, and assess interventions to ameliorate psychosocial impacts of climate change (see Doherty \& Clayton, this issue). Climate change will be accompanied by and itself epitomizes both natural and technological disasters of unprecedented consequence, and climate change has been framed as a truly global disaster and profound challenge for humanity (e.g. Spratt \& Sutton, 2008). It is important to acknowledge that some of the possible disasters associated with global climate change are not under conventional national jurisdiction and that responses to them may not be covered by conventional agencies, policies, or procedures. However, much of the existing and extensive body of psychological and social and health science research and practice on mitigation, preparedness, response, and recovery in the context of natural and technological disasters can still be applied and utilized (Elrod, Hamblen, Noris, 2006; Haskett, Scott, Nears, \& Grimmett, 2008; Reyes \& Jacobs, 2006) The disaster research literature with its transdisciplinary orientation has developed methodologies, measures, and many models and tools particularly apposite to the domain of psychology and climate change (e.g., Stokols et al., 2009). 
Psychological research in other areas, such as intergroup relations and processes, and perceived equity and procedural justice, may be useful when addressing conflicts that may emerge over environmental justice issues or among social groups as an indirect result of climate change and when developing and framing policy responses to climate change (Clayton \& Brook, 2005; Spence et al., 2009; Swim \& Clayton, 2010).

Psychology can also make important contributions to understanding and informing efforts to mitigate or limit climate change, although, as with other responses to climate change, responses are influenced by both individual and contextual factors. Much policy attention has been given to structural barriers to behavioral change, but Gifford (this issue) argues that removing these barriers is not likely to be sufficient because of other resistances to change. Some of these may relate to lack of understanding of climate change, while others relate to habitual behavioral patterns, bounded rationality, affective processes, personal and social motivations, and interpersonal processes (Gifford, this issue; Shogren, Parkhurst, Banerjee, 2010; Weber and Stern, this issue). For instance, psychological and social barriers include: hyperbolic discounting, which gives current outcomes more weight than temporally distant outcomes even when the latter outcomes are of greater value; reactance against policies perceived to reduce individual control; and perceived social norms that encourage energy use, to name a few.

Yet, as Stern (this issue) notes, psychologists have helped and can help design interventions to encourage actions to limit the human contribution to climate change at the individual, organizational, cultural, and policy levels. Psychologists have broadened understanding of why people do or do not respond to different types of interventions. They also provide and apply behavioral models that describe human and household behavioral contributions and have helped design effective interventions and evaluations to further develop 
and improve them. Some of these interventions provide better information so people know which actions have beneficial outcomes for themselves and for climate mitigation and adaptation. Psychologists design and test systems that make certain environmental choices more noticeable (e.g., energy-use feedback) or attractive (e,g., financial incentives that lower initial costs of energy-efficient equipment or move the financial benefits of the equipment temporally closer), or make environmentally beneficial actions more convenient, combining economic and noneconomic inducements to action in highly effective ways (Vandenbergh, Stern, Gardner, Dietz, \& Gilligan, 2010). They also suggest strategies to engage values that encourage contributions to the public good beyond those in an individual's self-interest. They help design informative messages and engage informal networks (e.g., in communities, on the Internet) that promote and activate social norms for participating in collective efforts to limit greenhouse gas emissions. They are beginning to examine behavioral factors in organizations that enable or inhibit reductions in organizations' contributions to climate change. Finally, they can help design and adapt formal and informal institutions at local to global levels that provide assurance to individual contributors that others will also contribute, thereby promoting coordinated and equitable responses. Psychologists not only help to improve public understanding and help inform personal and societal choices about proposed technological solutions; they also address how public understanding of the nature and impacts of climate change differ in important ways from climate change science accounts (Weber \& Stern, this volume), and how such individual and societal understandings also serve important psychological and cultural needs, with important adaptation and behavior change implications (e.g., Reser, 2010).

Fourth, psychology can make further important contributions to understanding how people think and feel about climate change, which in turn influences their motivations and 
behavioral responses to perceived and objective causes and consequences of climate change. As Gifford (this issue) notes, individuals perceive climate change differently depending upon their awareness of the problem, knowledge and certainty of the facts, and trust in experts, among other barriers. Furthermore, as Reser and Swim (this issue) and Thomas and Clayton (this issue) note, the threat and unfolding impacts of climate change may be experienced directly or indirectly. Direct encounters can range from the experience and distress of chronic stressors, such as drought and landscape change, to acute and cataclysmic weather events such as hurricanes, heat waves, and floods. Indirect experiences result from continuous exposure to multi-media coverage and representations, educational sources, and interpersonal interactions and exchange. Social constructions and representations of climate change can both reflect and influence sense-making and whether or not events are attributed to climate change. Weber and Stern (this issue) show that gaining a scientifically appropriate understanding of climate change is difficult because of a) the inherent difficulties of understanding the physical phenomena and the state of relevant scientific knowledge; b) psychological tendencies to rely on personal experience and simple mental models (both of which are often misleading; see also Gifford, this issue); and c) a wellorganized and ideologically motivated campaign to promote models of climate change that are at substantial variance with scientific evidence and broad consensus.

Stepping back from psychological contributions related to elements of the model illustrated in Figure 1, a number of characteristics of psychology as a discipline make it useful, if not crucial, for adequately addressing global climate change and its impacts. The most obvious contributions of psychology are at the individual level, where, as illustrated above, it can provide theoretical and empirical understanding of human causes, public risk perceptions and understandings, experienced impacts, and responses to climate change. This individual level of 
analysis also illustrates links between psychologically and environmentally significant behaviors and between adaptation and mitigation. For instance, individual efforts at mitigation may also benefit psychological adaptation to climate change.

Psychologists also examine individuals within natural and constructed physical and social contexts. Interpersonal, social-structural, and technological contexts affect behaviors that have important impacts on environmental systems (Clayton \& Brook, 2005; Gardner \& Stern, 2002; Wapner \& Demick, 2002). Attention to transactions and relationships between individuals and their natural and human-designed environments has long been a defining feature of environmental psychology (Gifford, 2007). Investigations at the intersection of psychology and the natural sciences, health sciences, humanities, and other social sciences can be particularly useful for addressing global climate change (Kazdin, 2009).

Psychologists have also uncovered individual, interpersonal, and social forces capable of explaining and changing human behavior in ways that others may fail to consider. Although people are, for the most part, able to articulate their opinions, beliefs, and preferences accurately, they are notoriously poor at recognizing the causes of their behavior (Nisbett \& Wilson, 1977; Li, Johnson, \& Zaval, 2010). This has been well demonstrated, for example, with the consumption of energy (Nolan, Schultz, Cialdini, Goldstein, \& Griskevicius, 2008). Behavioral investigations that employ experimental methodologies can identify psychological determinants of tradeoffs and choices made by people (Hardisty, Johnson, \& Weber, 2010; Weber, Johnson, Milch, Chang, Broadscholl, \& Goldstein, 2007) that collectively influence human contributions to climate change, including energy consumptive behaviors. These psychological determinants can be utilized in communication campaigns or in the design of decision environments to encourage people to reduce their energy consumption, to prevent such campaigns from being 
ineffective or, worse, inadvertently discouraging behavior change (e.g., Center for Research on Environmental Decisions, 2009). Psychological methodologies and measures can also aid in ongoing monitoring of behavioral changes, psychological impacts, and psychological processes that might otherwise be overlooked and that influence individuals' and communities' willingness and capacity to engage with adaptive change and the nature and forms of adaptations they select.

\section{Why Should Psychology Help Address Climate Change?}

Psychologists should help, first of all, because we can. Based on past research efforts and the knowledge base in the discipline, we believe that further efforts to improve understanding of the psychological processes related to climate change and effective incorporation and utilization of psychological knowledge in collaborative research and policy initiatives can help humanity effectively mitigate and adapt to climate change.

Second, the magnitude and potential irreversibility of global climate change and its likely psychological impacts and effects on quality of life and the environment prompt a consideration of ethical imperatives for psychologists' involvement. Climate change has the potential to have significant negative effects on global mental health, and these effects will likely be unevenly distributed (Page \& Howard, 2009; Costello, et al. 2009; Fritze, Blashki, Burke, \& Wiseman, 2008). In the near term, climate change probably will have a disproportionate direct impact on those of less economic privilege or social status (Agyeman, Bullard, \& Evans, 200; McMichael, Friel, Nyong Corvalan, 2008;) and, as with other environmental health issues (Bullard \& Johnson, 2000), social justice implications will demand consideration (e.g., Brown et al., 2010). Poverty and reduced individual preparedness and community-level resources for disaster relief are central to vulnerability to environmental risks (Brouwer, Akter, Bander, \& Haque, 2007). Natural disasters expose the inadequacies of mental health systems at the moment they are most 
needed (Sontag, 2010). Provision of mental health services in many low- and middle- income countries is already inadequate (Jacob, Sharan, Mirza, Garrido-Cumbrera, Seedat, Mari, Sreenivas, \& Saxena, 2007; Page \& Howard, 2009) and improvement in these services is challenged by economic crises and environmental disasters.

The APA Ethics Code, mission statement, and vision statements have direct implications in these local and global climate change contexts (APA, 2010a and b). They indicate that psychologists are committed to creating, communicating, and applying psychological knowledge in order to improve the conditions of and benefit individuals and society and to facilitate the resolution of global challenges. . Because global climate change presents both direct and indirect threats to individual and community mental health, climate change can be considered an appropriate arena of ethical obligation for psychologists (Doherty \& Clayton, this issue). As with other social issues on which psychologists have taken a stand (e.g., poverty, discrimination), climate change is an extremely consequential concern because it can harm psychological functioning, interpersonal and community relations, and human and nonhuman life, and because changes in thinking, motivation, and behavior are required for successful climate change mitigation and adaption. APA's ethical principles provide a basis for addressing social justice issues, such as disparities inherent in climate change impacts, and threats to the rights and welfare of persons who or communities which may be most vulnerable to climate change impacts (APA 2010, 2007). Increased efforts to highlight, study and address the psychological impacts of climate change do not pose obvious counter risks (Hansen, von Krauss \& Tickner, 2008). Indeed, awareness of psychological impacts may promote engagement in the issue and subsequent behavioral change.

APA ethical principles and standards also stress that psychologists must exercise 
reasonable judgment and recognize the boundaries of their competence. This recognition is essential for dealing with novel and complex interdisciplinary issues like global climate change. The standards also recognize that, in emerging areas in which recognized standards for training do not yet exist, psychologists should take reasonable steps to ensure the competence of their work and to protect those they work with and others from harm.. This also means that work needs to be done to broaden our competences in the domain of climate change and to continually develop new competencies as our understanding and the impacts of climate change unfold.

\section{How Can Psychologists Increase Their Contribution to the Science of Climate Change?}

Psychologists can be dramatically more effective if they relate and connect psychological work to constructs and perspectives developed in the broader climate research community and collaborate with scientists from other fields. Although psychologists have been investigating climate change and related subjects for decades and the discipline has a unique perspective and body of knowledge to contribute, the value of psychological contributions is not yet widely accepted nor are psychological insights and findings widely applied. The following principles can help maximize the value and use of psychological concepts, research, and perspectives for understanding the causes and impacts of climate change and informing effective responses to climate change:

1. Become conversant with language and research used in other social, engineering, and natural science fields that address climate change.

Anthropogenic climate change is an interdisciplinary issue with an emerging interdisciplinary vocabulary and language. Scientists from many disciplines readily understand human interactions with climate change in terms of human contributions or drivers, impacts or consequences, and responses. However, some terms have particular meanings or connotations in 
certain disciplines or discourses. Awareness of the language and concepts used by others and using this language and concepts when appropriate can aid communication. Differences between fields in the usage of certain terms and constructs may also reveal fundamental differences in perspective. When usage of the language of one field might result in confusion or a loss of meaning or clarity for a cross-disciplinary audience, it is important to be explicit about differences in usage. Adaptation, for example, has varying usages across disciplines that reflect differing favored levels of analysis and different conceptualizations of human responses. Clarifying such differences is one way psychologists can help improve overall understanding of climate change, communication between disciplines, and our own approaches to climate change.

Research from other fields can be important for interpreting the meaning or relevance of psychological variables, because their effects sometimes depend on factors and parameters that are more thoroughly understood in other fields. The reverse is also true. For example, the effectiveness of financial incentives for household energy efficiency depends on how people understand the available information and on the level of behavioral effort needed to take advantage of the incentive (Stern et al., 1986). Conversely, the effectiveness of information and persuasion depends on the economic incentives surrounding the behavior. A thorough understanding of the potential of psychological contributions to research and responses to climate change should be informed by knowledge from other social sciences, such as anthropology, geography, sociology, political science, communications research, and economics, as well as knowledge from engineering, business, and other fields. For example, individuals' understandings of climate change are affected by the psychological processes that influence seeking out and making sense of information as well as the activities of social movements and the judgments and decisions of journalists, editors and corporate media organizations. Thus, 
individual understandings of climate change are best understood by combining insights from psychology, sociology, communications research, and other social science fields (Weber \& Stern, this issue). This injunction to be interdisciplinary applies, of course, both to psychologists and non-psychologists.

2. Attend to psychological contributions that address issues recognized as important to climate science.

We psychologists must prioritize issues and behaviors recognized as important in terms of climate change causes, consequences, or responses. For example, in developing and describing psychological contributions to efforts to mitigate climate change, greater emphasis should be placed on changes that have large potential effects on emissions (e.g., using more fuelefficient means of transportation) than on changes that have smaller potential effects in terms of their technical potential (e.g., recycling household waste) and behavioral plasticity (e.g., traveling by carpool) (see Stern, this issue). The general public is not always aware of such differences in effectiveness (Attari et al., 2010). If findings about lower-impact behaviors are deemed important, that importance should be described in terms of the implications for climate change overall, perhaps by making the case that a principle established in studies of low-impact behaviors is generalizable to higher-impact behaviors. Similarly, when studying psychological consequences of climate change, psychologists should be prepared to indicate the broader importance and relevance of these consequences. For instance, the importance of affective or 'risk-as-feelings' responses (Loewenstein et al., 2001) may need to be explained to nonpsychologists. This could potentially be done in terms of how affective responses influence risk perceptions and subsequent willingness to change behaviors or support policies, how debilitating mental health outcomes influence preparation for, or responses to, the climate change impacts, or 
how the magnitude of these outcomes compares to the magnitude of other social phenomena (Ferguson \& Branscombe, 2010; Fritz, Blashki, Burke, Wiserman, 2008; Weber \& Stern, this issue).

In psychological research, findings typically are presented in terms of statistical significance, effect size, the proportion of people whose behavior changed (behavioral plasticity), or the amount of behavioral change measured as frequency or duration. However, what matters in the context of global climate change is the impact of causes or effects in environmental terms. For example, a good indicator of the impact of psychological variables on understanding human contributions to climate change is the amount of greenhouse gas emissions they can explain. The impact of a behavioral change on climate change depends on the combined effects of the number of individuals who might change their behavior, multiplied by the technical potential of the behavior to alter emissions and the plasticity of the behavior (the $I=t p n$ equation, see Stern, this issue). This is not to diminish the psychological significance and multiple benefits of taking personally meaningful actions in the context of climate change, and indeed such psychological significance mediates and enhances environmental significance. To demonstrate the importance of psychological variables for understanding human consequences of climate change, it is helpful to show how these variables affect the anticipation or experience of specific aspects of climate change and how these reactions affect major or widespread human consequences that are generally considered important.

3. Explain psychological contributions that are missing from others' analyses and that may be misunderstood by others, but be aware of the limitations of this research. Psychologists can provide climate researchers from other disciplines with psychological constructs that are relevant for understanding problems that other disciplines already recognize, 
and can correct misunderstandings and misuse of psychological constructs when these are encountered. For instance, psychologists can describe how the psychological processes of risk perception and stress management may alter people's willingness to make anticipatory adaptations to climate risks (Weber, 2006). As another example, disciplines vary in their tendency to focus on different levels of analysis. Psychologists can provide particular insight into the usefulness and importance of individual-level and experience-informed analyses and make connections between this level and more macro-level analyses (Winkel, Saegert \& Evans, 2010). However, we must be cognizant of the possibility that psychological phenomena are context-dependent. Psychological principles often are established in narrowly defined contexts: laboratory experiments, small-scale field experiments, and surveys of particular populations. To apply these principles to climate change, their external validity must be considered: One must consider whether the principles are applicable in other cultures or economies, in places with very different physical infrastructures or government regulations, or in vastly changed technological contexts that might appear a generation in the future For example, the effectiveness of an intervention to change commuting behavior (and therefore energy use) among college students has been demonstrated (Heath \& Gifford, 2002). However, without further research the effectiveness of the intervention beyond the population and time period studied may not apply. Psychologists must be careful not to claim that findings from any specific group have general applicability without evidence or strong theory to support such claims. Another example is the "foot-in-the-door effect" - the process by which inducing a small behavioral change can set in motion psychological changes that lead, over time, to larger behavioral changes. Efforts to change environmentally relevant behaviors with small environmental impacts (e.g., recycling) could possibly lead to change in more environmentally consequential behaviors (e.g., travel 
mode choice). Yet, available evidence raises questions about whether it operates with behaviors that affect climate (Thøgersen \& Crompton, 2009).

In speaking outside the discipline, we must be explicit about the extent to which psychological phenomena have been shown to operate in climate-relevant contexts and, if this has not been shown, be cautious about extrapolation from the contexts in which the phenomena have been established. Psychologists' expertise about preparing for and responding to natural disaster is likely applicable to climate change disasters. Yet, some inferences may be required if one considers climate change disasters to be both natural and technological (see Doherty \& Clayton, this issue). When considering psychological consequences of climate change, extrapolation is usually necessary because, except for the consequences of warnings about climate change, the most significant consequences lie in the future. Thus, extrapolations should be explicit about their evidence base and their likely applicability to projected future events.

\section{Be mindful of social disparities and ethical and justice issues that interface with climate} change appraisals, responses and impacts.

Much of the psychological research related to climate change has been conducted in the United States and Europe. Other populations may have different understandings of climate change and of the choices they face, which can in turn influence the social and psychological impacts of climate change. Understandings of, and responses to, climate change will be influenced by worldviews, cultures, and social identities (Bloodhart \& Swim, 2010; Clayton \& Myers, 2009; Heath \& Gifford, 2006; Swim \& Becker, 2010; Weber, 2010). Much climate science research in other disciplines has taken place in regions of the world such as parts of Africa, Asia, the Andes, Australia, and Alaska, where climate change impacts are far more evident and salient. Local populations in these areas have cultural vantage points, economies, 
and lifestyles far removed from the urban-based, highly industrialized, settings of much of North America and Europe. The influence of the mass media and contemporary information technologies also vary considerably across regions of the world. Other relevant differences within all countries reflect variation in demographic group membership (such as age, gender, and education), social identities, and the combinations of these factors. For example, gender differences in experiences with climate change and in climate change responses can vary by race, ethnicity, age, disabilities, religion, etc.

For both climate change adaptation and mitigation, cultural contexts and differences are likely to be important elements of the human dimensions of global climate change. Different cultural insights, perspectives, and experiences with disasters and adaptation can advance our understanding of the human causes of climate change, its impacts, and the means of responding to it. Cultural considerations will also be critical in providing suitable interventions and resources for communities that are experiencing dramatic upheavals as a result of global climate change. Different cultural meanings and social justice concerns can limit the applicability of existing research and may require attention when speaking with different populations. Finally, attending to social and cultural differences can further research by suggesting new ways of thinking about basic psychological processes and advancing interventions by forming sensitive cross-cultural and collaborative initiatives.

\section{Conclusion}

Global climate change provides an opportunity for greater integration of approaches within psychology as well as transdisciplinary cooperation with the other social sciences and the physical sciences. Such integration and collaboration typically best occurs around a common goal or problem. Global climate change presents a shared problem and daunting challenges, but 
this alone does not ensure cooperation. This article and this special issue are intended to help psychologists become more knowledgeable about how their disciplinary knowledge and expertise can inform collaborative discussions, research, and policy initiatives related to climate change adaptation and mitigation. More intensive engagement with non-psychologists will likely highlight the urgency, challenges, and importance of global climate change as a problem for psychological research; encourage teaching our students about the psychological aspects of climate change and human-environment transactions; and most importantly, help psychologists find ways to make their contributions more useful. Psychology has already made notable contributions to addressing climate change, but it can do much more, particularly in collaboration with others from diverse fields of interest. 


\section{References}

Agyeman, J. Bullard, R. \& Evans, B. (2003). Just sustainabilities: Development in an unequal world. London: Earthscan/The MIT Press.

American Psychological Association. (2007). The Road to Resilience. Retrieved June 15, 2009, from http://www.APAHelpCenter.org/resilience

American Psychological Association. (2010). American Psychological Association ethical principles of psychologists and code of conduct. Retrieved December 20, 2009, from http://www.apa.org/ethics/code/index.aspx?item=2.

American Psychological Association. (2010). American Psychological Association Mission Statement and Vision Statement. Retrieved December 20, 2009, from http://www.apa.org/about/index.aspx

American Psychological Association Task Force on the Interface Between Psychology and Global Climate Change (2009). Psychology and Global Climate Change: Addressing a Multi-faceted Phenomenon and Set of Challenges. Washington, DC: Author. Retrieved from http://www.apa.org/science/about/publications/climate-change.aspx.

Attari, S.Z., DeKay, M.L., Davidson, C.I., \& Bruine de Bruin, W. (2010). Public perceptions of energy consumption and savings. Proceedings of the National Aacademy of Sciences, $107,16054-16059$.

Bekin, C., Carrigan, M., \& Szmigin, I. (2005). Defying marketing sovereignty: Voluntary simplicity at new consumption communities. Qualitative Market Research: An International Journal, 8(4), 413-429. 
Bin, S., \& Dowlatabadi, H. (2005). Consumer lifestyle approach to US energy use and the related CO2 emissions. Energy Policy, 33(2), 197-208.

Black, J.S., Stern, P.C., \& Elworth, J. T. (1985). Personal and contextual influences on household energy adaptations. Journal of Applied Psychology, 무, 3-21.

Bloodhart, B. \& Swim, J.K. (2010). Equality, Harmony, and the Environment: An Ecofeminist Approach to Understanding the Role of Cultural Values on the Treatment of Women and Nature. Ecopsychology, 2, 187-194.

Brouwer, R.; Akter, S.; Brander, L.; Haque, E. (2007). Socioeconomic vulnerability and adaptation to environmental risk: A case study of climate change and flooding in Bangladesh. Risk Analysis, 27 313-326.

Brown, D., Tuana, N., Averill, M., Baer, P., Born, R., Brandão, C. E. L., Frodeman, R., et al. (2010). White Paper on the Ethical Dimensions of Climate Change. The Pennsylvania State University Rock Ethics Institute. Retrieved from http://rockethics.psu.edu/climate/whitepaper/edcc-whitepaper.pdf

Bullard, R., \& Johnson, G. S. (2000). Environmental Justice: Grassroots activism and its impact on public policy decision-making. Journal of Social Issues, 56, 555-578.

Center for Research on Environmental Decisions (2009). The Psychology of Climate Change Communication: A Guide for Scientists, Journalists, Educators, Political Aides, and the Interested Public. (http://www.cred.columbia.edu/guide/).

Chen, R. S., Boulding, E., \& Schneider, S. H., eds. (1983). Social science research and climate change: An interdiscìplinary appraisal. Dordrecht, Netherlands: Reidel.

Clayton, S., \& Brook, A. (2005). Can psychology help save the world? A model for conservation psychology. Analyses of Social Issues and Public Policy (ASAP). 5(1), 87-102. 
Clayton, S., \& Myers, G. (2009). Conservation psychology. Oxford, Wiley-Blackwell.

Costello A, Abbas M, Allen A, Ball S, Bell S, Bellamy R, Friel S, Groce N, Johnson A, Kett M, Lee M, Levy C, Maslin M, McCoy D, McGuire B, Montgomery H, Napier D, Pagel C, Patel J, de Oliveira JA, Redclift N, Rees H, Rogger D, Scott J, Stephenson J, Twigg J, Wolff J, Patterson C (2009). Managing the health effects of climate change: Lancet and University College London Institute for Global Health Commission. Lancet 373, 16931733.

Craig-Lees, M., \& Hill, C. (2002). Understanding voluntary simplifiers. Psychology \& Marketing, 19(2), 187-210.

Creyts, J., Granade, H.C., \& Ostrowski, K.J. (2010). U.S. energy savings: Opportunities and challenges. McKinsey Quarterly, January Issue.

Cvetkovich, G.T. and R. Werner. 1994. How Can Psychology Help Save the Planet?: A Research Agenda on Environmental Problems. Statement distributed by the APA Taskforce on Psychology and Environmental Problems. Washington, DC: American Psychological Association.

Elrod, C.L., Hamblen, J.L. \& Norris, F.H. (2006) Challenges in implementing disaster mental health programs. Annals of the American Academy of Political and Social Science, 604, 152-170.

Ferguson, M. A., \& Branscombe, N. R. (2010). Collective guilt mediates the effect of beliefs about global warming on willingness to engage in mitigation behavior. Journal of Environmental Psychology, In Press, Corrected Proof. doi:10.1016/j.jenvp.2009.11.010

Fischhoff, B., \& Furby, L. (1983). Psychological dimensions of climatic change. In Social Science research and climate change: An interdisciplinary appraisal. R. S. Chen, E. 
Boulding, S. H. Schneider (eds), pp. 180-203. Dordrecht: Reidel.

Fritze, J. G., Blashki, G. A., Burke, S. \& Wiseman, J. (2008). Hope, despair and transformation: Climate change and the promotion of mental health and wellbeing. International Journal of Mental Health Systems, 2(13). Retrieved April 30, 2009, from http://ijmhs.com/content/2/1/13.

Gardner, G.T., \& Stern, P.C. (2002). Environmental Problems and Human Behavior. (2 ${ }^{\text {nd }}$ ed.). Boston: Pearson Custom Publishing.

Gifford, R. (2006). A general model of social dilemmas. International Journal of Ecological Economics and Statistics, 5, 23-40.

Gifford, R. (2007). Environmental psychology and sustainable development: Expansion, maturation, and challenges. Journal of Social Issues. Vol 63(1), 199-212.

Gifford, R. (2008). Psychology's Essential Role in Alleviating the Impacts of Climate Change. Canadian Psychology-Psychologie Candadienne, 49(4), 273-280.

Hansen, S. F.; von Krauss, M. K.; Tickner, J. A. (2008). The precautionary principle and riskrisk tradeoffs. Journal of Risk Research, 11, 423-464.

Hardisty, D. H., Johnson, E.J., \& Weber, E.U. (2010). A dirty word or a dirty world? Attribute framing, political affiliation, and query theory. Psychological Science, 21, 86-92.

Haskett, M. E., Scott, S. S., Nears, K., \& Grimmett, M. A. (2008). Lessons from Katrina: Disaster mental health service in the Gulf Coast region. Professional Psychology: Research and Practice. Vol 39(1), 93-99.

Heath, Y., \& Gifford, R. (2002). Extending the theory of planned behavior: Predicting the use of public transportation. Journal of Applied Social Psychology, 32, 2154-2185. 
Heath, Y., \& Gifford, R. (2006). Free-market ideology and environmental degradation: The case of belief in global climate change. Environment and Behavior, 38, 48-71.

Intergovernmental Panel on Climate Change. (2007a). Climate change 2007 : The physical science basis. Contribution of Working Group I to the Fourth Assessment Report of the Intergovernmental Panel on Climate Change. New York, NY: Cambridge University Press.

Intergovernmental Panel on Climate Change. (2007b). Climate change 2007: Impacts, adaptation, and vulnerability. Contribution of Working Group II to the Fourth Assessment Report of the Intergovernmental Panel on Climate Change. New York, NY: Cambridge University Press.

Jacob, K., Sharan, P., Mirza, I., Garrido-Cumbrera, M., Seedat, S., Mari, J., Sreenivas, V. \& Saxena, S. (2007). Mental health systems in countries: Where are we now? Lancet 370, $1061-1077$.

Karl, T., Melillo, J.M., \& Peterson, T.C. (2009). Global Climate Change Impacts in the United States: A State of Knowledge Report from the U.S. Global Change Research Program. New York, NY: Cambridge University Press.

Kates, R. W., Ausubel, J., \& Berberian, M. (Eeds). (1985). Climate impact assessment: studies of the interaction of climate and society. New York: Wiley.

Kazdin, A. E. (2009). Psychological science's contributions to a sustainable environment: Extending our reach to a grand challenge of society. American Psychologist. 64(5), 339356.

Kopelman, S., Weber, J,M., \& Messick, D.M. (2002) Factors influencing cooperation in commons dilemmas: A review of experimental psychological research. pp. 113-156 in 
National Research Council. The drama of the commons. (E. Ostrom, T. Dietz, N. Dolsak, Stern, P.C., Stonich, S., \& Weber, E.U., Eds.) Washington: National Academy Press. Koger, S.M., Winter, D.D. (2010) The Psychology of Environmental Problems Psychology for Sustainability 3rd Edition. USA, Psychology Press.

Li, Y., Johnson, E.J., \& Zaval, L. (2010). Local warming: Daily variation in temperature affects beliefs and concern for climate change. Under review, Psychological Science.

Loewenstein, G. F., Weber, E. U., Hsee, C. K., Welch, E. (2001). Risk as feelings. Psychological Bulletin, 127, 267-286.

McMichael, AJ, Friel, S, Nyong A, Corvalan, C (2008). Global environmental change and health: impact, inequalities, and the health sector. British Medical Journal 336, 191-194.

National Research Council. (1992). Global environmental change: Understanding the human dimensions. (P.C. Stern, O.R. Young, and D. Druckman, Eds.) Washington: National Academy Press.

National Research Council. (1999). Human dimensions of global environmental change: Pathways for the next decade. Washington: National Academy Press.

National Research Council. (2002). The Drama of the commons. (E. Ostrom, T. Dietz, N. Dolsak, Stern, P.C., Stonich, S., \& Weber, E.U., Eds.) Washington: National Academy Press.

National Research Council. (2010a). Advancing the science of climate change. Washington: National Academies Press.

National Research Council. (2010b). Adapting to the impacts of climate change. Washington: National Academies Press.

Nickerson, R.S. (2003). Psychology and environmental change. Mahwah, NJ: Lawrence 
Erlbaum Associates.

Nisbett, R. E., \& Wilson, T. D. (1977). Telling more than we can know: Verbal reports on mental processes. Psychological Review. 84(3), 231-259.

Nolan, J. M., Schultz, P. W., Cialdini, R. B., Goldstein, N. J., \& Griskevicius, V. (2008). Normative social influence is underdetected. Personality and Social Psychology Bulletin. 34(7), 913-923.

Page, L. \& Howard, L. (2009). The impact of climate change on mental health (but will mental health be discussed at Copenhagen?) Psychological Medicine, 1-4.

Reser, J.P. (2010) Public understandings of climate change: Reflections and reframing. Risk Analysis, in press.

Reyes, G. \& Jacobs, G.A. (2006) (Eds) Handbook of international disaster psychology, Vols 1-4. Westport, CT: Praeger.

Schmuck, P. \& Schultz, W. P. (2002). (Eds). The psychology of sustainable development. Dordrecht, Netherlands: Kluwer Academic Publishers.

Shogren, J.R., Parkhurst, G., \& Banerjee, P. (2010). Two cheers and a qualm for behavioral environmental economics. Environmental and Resource Economics, 46(2), 235-247.

Sjöberg, L. (1989). Global change and human action: psychological perspectives. International Social Science Journal, 41:413-32.

Solomon, S., Plattner, G., Knutti, R., \& Friedlingstein, P. (2009). Irreversible climate change due to carbon dioxide emissions. Proceedings of the National Academy of Sciences, 106(6).

Sontag, D. (2010, March 20) Mental health care in Haiti goes from bad to horrid. The New York Times.

Spence, A., Pidgeon, N., \& Uzzell, D. (2009). Climate change: Psychology's contribution. The 
Psychologist. 22(2), 108-111.

Spratt, D. \& Sutton, P. (2008) Climate code red: The case for a sustainable emergency. Fitzroy, Melbourne: Friends of the Earth. www.climatecodered.net

Stern, P.C. (1986). Blind spots in policy analysis: What economics doesn't say about energy use. Journal of Policy Analysis and Management, 5, 200-227.

Stern, P.C. (1992). Psychological dimensions of global environmental change. Annual Review of Psychology, 43, 269-302.

Stern, P.C. (1997). Toward a working definition of consumption for environmental research and policy. pp. 12-35 in National Research Council, Environmentally significant consumption: Research directions. (Stern, P. C., Dietz, T., Ruttan, V. R., Socolow, R. H., \& Sweeney, J. L., Eds.). Washington: National Academy Press.

Stern, P.C. (1993). A second environmental science: Human-environment interactions. Science, 260, 1897-1899.

Stokols, D., Misra, S., Runnerstrom, M.G. \& Hipp, A. (2009) Psychology in an age of ecological crisis. American Psychologist, 64, 181-193.

Swim, J.K., \& Becker, J. (2010). Individuals' efforts to mitigate global climate change: A comparison of U.S. versus German residents engagement in direct and indirect energy reduction behaviors.. Paper under review.

Swim, J.K., \& Clayton, S. (2010). SPSSI and Global Climate Change. To be posted at http://www.spssi.org.

Thøgersen, J., \& Crompton, T. (2009). Simple and painless? The limitations of spillover in environmental campaigning. Journal of Consumer Policy, 32, 141-163.

Uzzell, D., \& Räthzel, N. (2009). Transforming environmental psychology. Journal of 
Environmental Psychology. 29(3), 340-350.

Vandenbergh, M.P., Stern, P.C., Gardner, G.T., Dietz, T., and Gilligan, J. (2010). Implementing the behavioral wedge: Designing and adopting effective carbon emissions reduction programs. Environmental Law Reporter, 40, 10545-10552.

Vlek, C., \& Steg, L. (2007). Human Behavior and Environmental Sustainability: Problems, Driving Forces, and Research Topics. Journal of Social Issues, 63(1), 1-19.

Wapner, S., \& Demick, J. (2002). The increasing contexts of context in the study of environment behavior relations. Bechtel, Robert B.; Churchman, Arza (2002). Handbook of environmental psychology. (pp. 3-14). Hoboken, NJ, US: John Wiley \& Sons Inc. xiii.

Weber, E. U. (2006). Experience-based and description-based perceptions of long-term risk: Why global warming does not scare us (yet). Climatic Change, 70, 103-120.

Weber, E. U. (2010). What shapes perceptions of climate change? Wiley Interdisciplinary Reviews: Climate Change, Online Publication.

Weber, E. U., Johnson, E. J., Milch, K., Chang, H., Brodscholl, J., \& Goldstein, D. (2007). Asymmetric discounting in intertemporal choice: A query theory account. Psychological Science, $18,516-523$.

Winkel, G., Saegert, S., Evans, G.W. (2010). An ecological perspective on theory, methods, and analysis in environmental psychology: Advances and challenges. Journal of Environmental Psychology, 29, 318-328.

WHO | Climate change and human health. (2010). Retrieved May 3, 2010, from http://www.who.int/globalchange/en/ 
Psychology and Global Climate Change 34

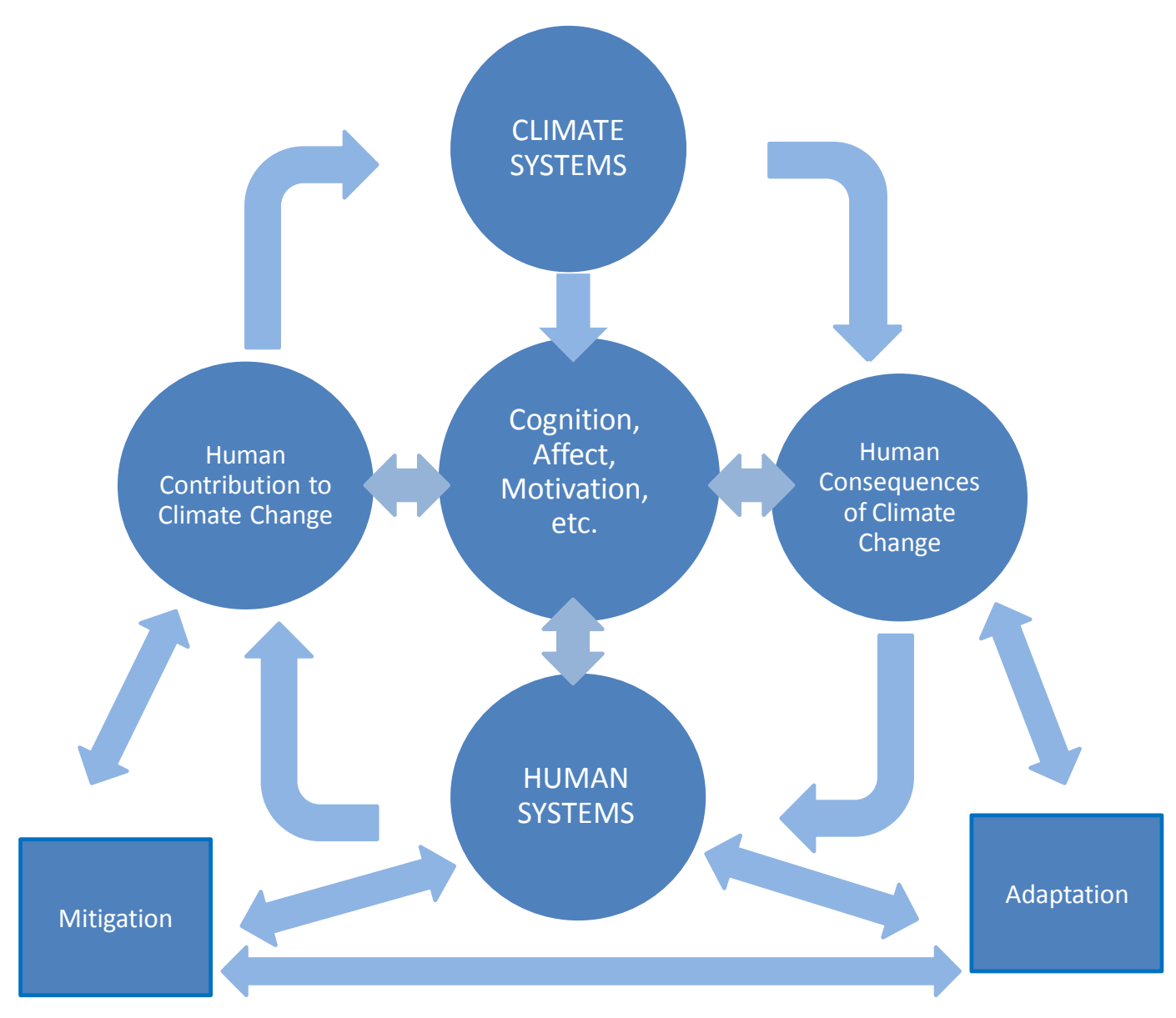

Figure 1: Illustration of human and psychological dimensions of climate change. 